\title{
Assessment of calprotectin in ascitic fluid as a marker for spontaneous bacterial peritonitis diagnosis in cirrhotic patients
} Fayrouz O. Selim ${ }^{a}$, Nahawand A. El-Deeb ${ }^{a}$, Hesham A. Farrag ${ }^{a}$, Azza M. Ahmed ${ }^{\text {b }}$

\author{
Departments of anternal Medicine, ${ }^{b}$ Clinical \\ Pathology, Faculty of Medicine, Zagazig \\ University, Zagazig, Egypt \\ Correspondence to Fayrouz O. Selim, MD, \\ Department of Internal Medicine, Faculty of \\ Human Medicine, Zagazig University, \\ Endocrinology Unit, Egypt. Sharkyia \\ Governorate, Zagazig City, Postal Code: \\ 44519. Tel: +201278528404; \\ fax: +20552368567 ; \\ e-mail: feroo02012@hotmail.com \\ Received 24 March 2018 \\ Accepted 25 July 2018
}

The Egyptian Journal of Internal Medicine 2018, 30:223-230

\begin{abstract}
Background
Spontaneous bacterial peritonitis (SBP) is a serious infection of ascitic fluid in cirrhotic patients. High mortality associated with the delay in diagnosis and treatment. There is a need for an accurate and a rapid method for SBP diagnosis. Objectives

We aimed to evaluate ascitic fluid calprotectin as a diagnostic marker for SBP.

Patients and methods

Forty four cirrhotic patients were divided into two groups, non-SBP group: 22 patients with cirrhotic ascites without evidence of SBP and SBP group: 22 patients with cirrhotic ascites and SBP diagnosed by positive ascitic fluid bacterial culture and an increase in polymorphonuclear leukocytes (PMNLs) count in ascites ( $\geq 250$ cells $/ \mathrm{mm}^{3}$ ). Ascitic fluid calprotectin levels were measured using enzyme-linked immunosorbent assay.

Results

There was a significant increase of ascitic fluid calprotectin, total leukocytic count, PMNLs, lactate dehydrogenase, and total protein in SBP group when compared to non-SBP group. There were significant positive correlations between white blood cell, ascitic fluid total leukocytic count, PMNLs, total protein, and model for endstage liver disease score values and ascitic fluid calprotectin among SBP group. Ascitic fluid calprotectin with cutoff value $620 \mathrm{ng} / \mathrm{ml}$, showed a sensitivity of $90.91 \%$ and a specificity of $95.45 \%$, in diagnosis of SBP with positive predictive value $95.2 \%$ and negative predictive value $91.3 \%$.

Conclusion
\end{abstract}

Ascitic fluid calprotectin may be valuable in rapid diagnosis of SBP.

Keywords:

ascites, calprotectin, spontaneous bacterial peritonitis

Egypt J Intern Med 30:223-230

(c) 2019 The Egyptian Journal of Internal Medicine

$1110-7782$

\section{Introduction}

Spontaneous bacterial peritonitis (SBP) is a bacterial infection of previously sterile ascitic fluids, in absence of a gastrointestinal perforation and an intraabdominal inflammatory lesions like abscess, cholecystitis, or acute pancreatitis [1]. Gut bacteria is the most common organisms that infect the ascitic fluid [2].

SBP is responsible for 10-30\% of SBP patients getting admitted in the hospital [3]. In patients with SBP, death rate ranges from 40 to $70 \%$. The mortality may decrease with rapid management of SBP [4].

SBP on admission had mortality rates up to $15 \%$, and patients who recovered from a first SBP episode had decreased survival in comparison to cirrhotic patients without history of SBP [5].

About $10 \%$ of the patients with SBP are asymptomatic, so diagnostic paracentesis should be performed in all patients who presented with signs or symptoms of SBP (e.g. abdominal pain and fever), kidney or liver function impairment, gastrointestinal tract (GIT) hemorrhage, and hepatic encephalopathy [3].

SBP diagnosis was established by the presence of a polymorphonuclear leukocytes (PMNLs) count in ascitic fluid more than $250 \mathrm{cells} / \mathrm{mm}^{3}$ without an intra-abdominal infection source [6].

Ascitic fluid leukocytic count and differential have low cost and ease of performance manually using light microscopy. But, the diagnosis is often delayed. So, automated PMNL counter have been used but its diagnostic accuracy is limited [7].

This is an open access journal, and articles are distributed under the terms of the Creative Commons Attribution-NonCommercial-ShareAlike 4.0 License, which allows others to remix, tweak, and build upon the work non-commercially, as long as appropriate credit is given and the new creations are licensed under the identical terms. 
As rapid diagnosis of SBP and antibiotic treatment initiation is very important. Therefore, an accurate and effective method of rapid diagnosis of SBP is needed.

Calprotectin is a calcium and zinc-binding protein and detected mainly in neutrophils. Its presence in body fluids is directly proportional to the rate of influx of neutrophils [8].

Neutrophils are acute inflammatory cells, which increase in the early inflammatory phases. Since they secrete most inflammatory factors, which include antibacterial proteins, enzymes, and cytokines [9].

Calprotectin is present mainly in neutrophils, macrophages, and very rarely appears in lymphocytes. Calprotectin account for about $60 \%$ of cytosolic proteins of neutrophils [9].

Ascitic fluid calprotectin may be helpful in detection of neutrophil count more than 250 cells $/ \mathrm{mm}^{3}$, it has an important role in diagnosis of SBP and this will be a rapid bedside test in quick treatment of SBP [7].

This study is designed to evaluate the changes in ascitic fluid calprotectin concentrations in patients with SBP to detect its role in the SBP diagnosis.

\section{Patients and methods}

This cross-sectional study was carried out in hepatogastroenterology subunit of medical ICU and Clinical Pathology Department, Faculty of Medicine, Zagazig University, in the period from September 2016 to April 2017, which included a total number of 44 patients with cirrhotic ascites. The patients were divided into two groups:

(1) Non-SBP group: it included 22 patients with cirrhotic ascites without clinical or laboratory evidence of SBP.

(2) SBP group: it included 22 patients with cirrhotic ascites with SBP. They were diagnosed by positive ascitic fluid bacterial culture, an increase in PMNLs count in ascites $\left(>250\right.$ cells $\left./ \mathrm{mm}^{3}\right)$ and without any intra-abdominal source of infection.

\section{Exclusion criteria}

Cirrhotic patients with and without SBP receiving antibiotics in last 1 week; recent abdominal surgery ( $<3$ months); abdominal malignancy [hepatocellular carcinoma (HCC), colorectal carcinoma, gastric carcinoma, pancreatic carcinoma, cholangiocarcinoma]; intra-abdominal infected lesions, such as abscess, appendicitis, cholecystitis, and pancreatitis; history of inflammatory bowel disease (Crohn's disease, ulcerative colitis) as well as patients with heart failure (HF), hematological, and autoimmune disorders were excluded.

\section{Ethical clearance}

Written informed consent was taken from the patients to participate in the study. Approval for performing the study was obtained from Internal Medicine and Clinical Pathology Departments, Zagazig University Hospital after taking Institutional Review Board approval.

All included patients were subjected to full history and thorough clinical examination with special stress on manifestations of liver cell failure, SBP, and possible complications, such as variceal bleeding and hepatic encephalopathy.

\section{Routine investigations}

Routine investigations included complete blood picture, liver chemistry [serum alanine aminotransferase (ALT) and aspartate aminotransferase (AST), total and direct serum bilirubin, serum total protein and albumin, prothrombin time, concentration, and international normalization ratio (INR)], renal function tests (serum creatinine and urea), and serological tests for viral markers. Abdominal ultrasonography was used to assess amount of ascites, liver and spleen size, liver echogenicity, and focal lesions.

\section{Diagnostic abdominal paracentesis}

It was done for ascitic cirrhotic patients at admission, who developed symptoms or signs of SBP during hospitalization, such as fever, abdominal pain, or changes in gastrointestinal motility (vomiting, diarrhea, or ileus).

Paracentesis was explained to the patient and it was done under ultrasonographic guidance and aseptic precautions using a wide bore needle.

Three samples of ascitic fluid, each of $5 \mathrm{~cm}$, were taken from each patient at the time of admission and sent immediately for physical, biochemical [total protein content, albumin, glucose, lactate dehydrogenase (LDH), and calprotectin], white blood cells (WBCs) (total and differential), red blood cells counting, and $25 \mathrm{ml}$ for microbiological cultures and sensitivity. Serum-ascites albumin gradient was also estimated.

\section{Assessment of severity of liver cirrhosis}

By calculation of Child's Pugh score and model for end-stage liver disease (MELD) score. 


\section{Specific investigation}

Ascitic fluid calprotectin was measured by enzymelinked immunosorbent assay. The kit was supplied from Sunred-Bio (Shanghai, China).

\section{Statistical analysis}

Variables was computerized and analyzed using SPSS version 19 (SPSS Inc, Chicago, IL, USA).

\section{Results}

\section{Patient characteristics}

Out of 70 patients, only 44 patients with ascites were included in this study. According to ascitic fluid analysis and clinical data, they were divided into a SBP group including 22 patients (16 males and six females) with mean age of $55.95 \pm 8.16$ years and nonSBP group of 22 patients (17 males and five females) with mean age of $55.5 \pm 8.75$ years.

Patients suffered from liver cirrhosis with different etiologies, $33(75 \%)$ chronic hepatitis C-related cirrhosis, six $(13.63 \%)$ chronic hepatitis B-related cirrhosis, two (4.55\%) nonalcoholic steatohepatitisrelated cirrhosis, two (4.55\%) autoimmune-related cirrhosis, and one (2.27\%) cryptogenic cirrhosis (Table 1).

The majority of both groups were child C (68.2\% in SBP group and 54.5\% in non-SBP group) but without statistically significant difference with respect to Child-Pugh score. Whereas MELD score mean values were significantly higher in SBP group than in non-SBP group (Table 2).

Fever followed by abdominal pain, hepatic encephalopathy, and upper GIT bleeding were the

Table 1 Etiology of liver cirrhosis

\begin{tabular}{lc}
\hline Variables & Number of patients $(44)[n(\%)]$ \\
\hline Chronic hepatitis C & $33(75)$ \\
Chronic hepatitis B & $6(13.63)$ \\
Nonalcoholic steatohepatitis & $2(4.55)$ \\
Autoimmune hepatitis & $2(4.55)$ \\
Cryptogenic cirrhosis & $1(2.27)$ \\
\hline
\end{tabular}

common presenting symptoms in SBP group (72.7, $59.1,54.5,40.9 \%$ ), respectively, while in non-SBP groups, diarrhea followed by nausea and vomiting and hepatic encephalopathy were the common presenting symptoms (59.1, 45.5, 31.8\%), respectively. There was high statistical significance increase in number of cases presented with fever, abdominal pain, and upper GIT bleeding in SBP group compared with non-SBP group. Whereas, inbetween both the groups there was no significant difference with respect to hepatic encephalopathy, nausea, vomiting, and diarrhea (Table 3 ).

\section{Laboratory and ascitic fluid cell count}

Among the study population of SBP the culture results showed growth of Escherichia coli (12 isolates) followed by Streptococcus viridans (six isolates), Klebsiella pneumoniae (two isolates), and Staphylococcus aureus (two isolates) in SBP group (Table 4).

There was a significant increase in WBC, ALT, AST, total bilirubin, INR, and creatinine with a significant decrease in platelets and albumin in SBP group versus the non-SBP group. In addition, there was a significant increase in ascitic fluid total leukocytic count (TLC), PMNLs, total protein, LDH, and calprotectin in SBP group versus the non-SBP group (Table 5).

\section{Diagnostic value of ascitic calprotectin}

There was a positive correlation between ascitic fluid calprotectin, WBC, and MELD score values while a negative correlation was found between ascitic fluid calprotectin and serum albumin in SBP group. Also, there was a positive correlation between ascitic fluid calprotectin and ascitic fluid TLC, PMNLs, and total protein but negative correlation between ascitic calprotectin and ascitic albumin among SBP group (Table 6).

From the receiver operating characteristic curve, at cutoff value of $(620 \mathrm{ng} / \mathrm{ml})$, ascitic fluid calprotectin showed a sensitivity of $90.91 \%$ and a specificity of 95.45\% for detecting SBP (area under curve=0.967) with negative predictive value (NPV) and positive

Table 2 The severity of liver disease in the studied groups

\begin{tabular}{|c|c|c|c|c|}
\hline Variables & Non-SBP group & SBP group & Test & $P$ value \\
\hline \multicolumn{5}{|l|}{ Child-Pugh $[n(\%)]$} \\
\hline Child A & $0(0.0)$ & $0(0.0)$ & $\chi^{2}=0.863$ & 0.353 \\
\hline Child B & $10(45.5)$ & 7 (31.8) & & \\
\hline Child C & $12(54.5)$ & $15(68.2)$ & & \\
\hline MELD score $($ mean $\pm S D)$ & $15.0 \pm 5.80$ & $18.70 \pm 7.42$ & $t=2.186$ & $0.034^{*}$ \\
\hline
\end{tabular}

$t$, independent $t$ test. $\chi^{2}$, Chi square test. MELD, model for end-stage liver disease; SBP, spontaneous bacterial peritonitis. ${ }^{*}$ Significant difference $(P<0.05)$. 
predictive value (PPV) of 91.3 and $95.2 \%$, respectively (Table 7).

\section{Discussion}

Ascites is a common complications in patients with liver cirrhosis. It shows poor prognosis. The course depends on the underlying liver disease that causes ascites and its response to the therapy [10].

SBP is a bacterial infection of ascitic fluid in the absence of any intra-abdomen source of infection [1]. It is responsible for $10-30 \%$ of all reported bacterial infections in patients admitted in the hospital [5]. It is also one of the dangerous

Table 3 Clinical presentation of the studied groups

\begin{tabular}{lcccc}
\hline Variables & $\begin{array}{c}\text { Non-SBP } \\
\text { group }(N=22) \\
{[n(\%)]}\end{array}$ & $\begin{array}{c}\text { SBP group } \\
(N=22) \\
{[n(\%)]}\end{array}$ & $\chi^{2}$ & $\begin{array}{c}P \\
\text { value }\end{array}$ \\
\hline $\begin{array}{lcccc}\text { Fever } \\
\text { Abdominal pain }\end{array}$ & $2(9.1)$ & $16(72.7)$ & 18.427 & $0.000^{*}$ \\
$\begin{array}{l}\text { Hepatic } \\
\text { encephalopathy }\end{array}$ & $7(31.8)$ & $13(59.1)$ & 12.239 & $0.000^{*}$ \\
$\begin{array}{l}\text { Upper GIT } \\
\text { bleeding }\end{array}$ & $3(13.6)$ & $9(40.9)$ & 4.125 & $0.042^{*}$ \\
$\begin{array}{l}\text { Nausea and } \\
\text { vomiting }\end{array}$ & $10(45.5)$ & $8(36.4)$ & 0.376 & 0.540 \\
Diarrhea & $13(59.1)$ & $7(31.8)$ & 2.292 & 0.130 \\
\hline
\end{tabular}

GIT, gastrointestinal tract; $\chi^{2}$, Chi square test; SBP, spontaneous bacterial peritonitis. *Significant difference $(P<0.05)$ complications in cirrhotic patients with a mortality rate that reaches $30-50 \%$ [11].

The absence of clinical manifestations in some patients with SBP makes the dependence on reliable marker is an important item, taking into consideration that SBP is one of the most frequent and important complications found in patients with liver cell failure [12].

In clinical practice the diagnosis of SBP depend on PMNLs that must be more than or equal to $250 \mathrm{cell} / \mu 1$ in ascitic fluid in absence of infection in the abdomen. However, TLC and PMNLs counts in ascitic fluid are not always readily available [13].

Calprotectin, a calcium and zinc-binding protein that belong to the $\mathrm{S} 100$ protein family. It is detected almost mainly in neutrophils, and its presence in body fluids is proportional to the flow of neutrophils. Calprotectin is

Table 4 Isolated organisms in the culture of ascitic fluid in spontaneous bacterial peritonitis group

\begin{tabular}{lc}
\hline Isolates & $n(\%)$ \\
\hline No growth & $0(0.0)$ \\
Escherichia coli & $12(54.5)$ \\
Streptococcus viridans & $6(27.3)$ \\
Klebsiella pneumoniae & $2(9.1)$ \\
Staphylococcus aureus & $2(9.1)$ \\
\hline
\end{tabular}

Table 5 Biochemical parameters in the studied groups

\begin{tabular}{|c|c|c|c|c|}
\hline Variables & Non-SBP group $(N=22)$ & SBP group $(N=22)$ & $t$ test & $P$ value \\
\hline HB (g/dl) & $9.24 \pm 1.23$ & $8.82 \pm 0.99$ & 1.239 & 0.222 \\
\hline WBC $\times 10^{3}\left(\mathrm{cell} / \mathrm{mm}^{3}\right)$ & $5.33 \pm 1.68$ & $12.11 \pm 3.90$ & 7.464 & $0.000^{*}$ \\
\hline PLT $\times 10^{3}\left(\mathrm{cell} / \mathrm{mm}^{3}\right)$ & $113.95 \pm 19.39$ & $90.18 \pm 17.41$ & 4.279 & $0.000^{*}$ \\
\hline FBG (mg/dl) & $109.05 \pm 14.87$ & $115.27 \pm 19.76$ & 1.181 & 0.244 \\
\hline ALT (IU/I) & $39.59 \pm 10.93$ & $72.73 \pm 13.44$ & 8.972 & $0.000^{*}$ \\
\hline AST (IU/I) & $60.0 \pm 15.031$ & $73.59 \pm 15.22$ & 2.953 & $0.005^{\star}$ \\
\hline Total bilirubin (mg/dl) & $1.75 \pm 0.35$ & $2.58 \pm 0.78$ & 4.607 & $0.000^{*}$ \\
\hline Albumin (g/dl) & $2.99 \pm 0.12$ & $2.63 \pm 0.27$ & 5.712 & $0.000^{*}$ \\
\hline INR & $1.54 \pm 0.18$ & $1.70 \pm 0.18$ & 2.947 & $0.005^{\star}$ \\
\hline Creatinine (mg/dl) & $1.48 \pm 0.29$ & $1.85 \pm 0.48$ & 3.149 & $0.003^{*}$ \\
\hline \multicolumn{5}{|l|}{ Ascitic fluid analysis } \\
\hline TLC $($ cell/mm³) & $200.56 \pm 50.13$ & $940.91 \pm 189.38$ & 17.726 & $0.000^{*}$ \\
\hline PMNLs (cell/mm³) & $71.05 \pm 34.61$ & $385.68 \pm 90.55$ & 15.224 & $0.000^{*}$ \\
\hline Total protein (g/dl) & $1.52 \pm 0.23$ & $1.82 \pm 0.26$ & 4.054 & $0.000^{*}$ \\
\hline Albumin (g/dl) & $0.77 \pm 0.21$ & $0.76 \pm 0.17$ & 0.160 & 0.874 \\
\hline Glucose (mg/dl) & $96.32 \pm 11.77$ & $93.82 \pm 12.71$ & 0.677 & 0.502 \\
\hline LDH (IU/I) & $204.23 \pm 28.54$ & $284.95 \pm 43.34$ & 7.296 & $0.000^{*}$ \\
\hline SAAG (g/dl) & $1.9 \pm 0.22$ & $1.87 \pm 0.29$ & 0.387 & 0.701 \\
\hline Ascitic fluid calprotectin (ng/ml) & $294.91 \pm 17.48$ & $781.23 \pm 165.94$ & 8.339 & $0.000^{*}$ \\
\hline
\end{tabular}

Data are presented as mean \pm SD. $t$ test, independent $t$ test. ALT, alanine aminotransferase; AST, aspartate aminotransferase; FBG, fasting blood glucose; HB, hemoglobin; INR, international normalization ratio; LDH, lactate dehydrogenase; PLT, platelets; PMNLs, polymorphnuclear leukocytes; SAAG, serum-ascites albumin gradient; SBP, spontaneous bacterial peritonitis; TLC, total leukocytic count; WBC, white blood cell. *Significant difference $(P<0.05)$. 
Table 6 Correlation between ascitic fluid calprotectin and different parameters in the studied groups

\begin{tabular}{|c|c|c|c|c|}
\hline \multirow[b]{2}{*}{ Variables } & \multicolumn{2}{|c|}{ Non-SBP group $(N=22)$} & \multicolumn{2}{|c|}{ SBP group $(N=22)$} \\
\hline & $r$ & $P$ & $r$ & $P$ \\
\hline WBC $\times 10^{3}\left(\mathrm{cell} / \mathrm{mm}^{3}\right)$ & -0.393 & 0.070 & $0.723^{\star *}$ & $0.000^{*}$ \\
\hline $\operatorname{PLT} \times 10^{3}\left(\mathrm{cell} / \mathrm{mm}^{3}\right)$ & -0.022 & 0.924 & 0.223 & 0.317 \\
\hline ALT (IU/I) & -0.022 & 0.922 & 0.057 & 0.803 \\
\hline AST (IU/I) & 0.026 & 0.907 & 0.208 & 0.352 \\
\hline Total bilirubin $(\mathrm{mg} / \mathrm{dl})$ & -0.362 & 0.062 & 0.183 & 0.872 \\
\hline Albumin (g/dl) & -0.323 & 0.143 & $-0.742^{\star \star}$ & $0.000^{*}$ \\
\hline INR & -0.037 & 0.871 & 0.244 & 0.273 \\
\hline TLC $\left(\right.$ cell $\left./ \mathrm{mm}^{3}\right)$ in ascitic fluid & 0.104 & 0.644 & $0.757^{\star \star}$ & $0.000^{*}$ \\
\hline PMNLs $\left(\right.$ cell $/ \mathrm{mm}^{3}$ ) in ascitic fluid & 0.160 & 0.478 & $0.951^{* *}$ & $0.000^{*}$ \\
\hline Albumin (g/dl) in ascitic fluid & 0.202 & 0.366 & $-0.600^{\star *}$ & $0.003^{*}$ \\
\hline Total protein $(\mathrm{g} / \mathrm{dl})$ in ascitic fluid & 0.201 & 0.369 & $0.449^{*}$ & $0.036^{*}$ \\
\hline Glucose $(\mathrm{mg} / \mathrm{dl})$ in ascitic fluid & 0.124 & 0.582 & 0.294 & 0.185 \\
\hline LDH (IU/I) in ascitic fluid & 0.349 & 0.111 & 0.221 & 0.324 \\
\hline SAAG (g/dl) & 0.223 & 0.317 & 0.357 & 0.102 \\
\hline Child score & 0.172 & 0.443 & 0.106 & 0.638 \\
\hline MELD score & 0.167 & 0.711 & $0.761^{\star \star}$ & 0.000 \\
\hline
\end{tabular}

$r$, Pearson's correlation tests. ALT, alanine aminotransferase; AST, aspartate aminotransferase; INR, international normalization ratio; LDH, lactate dehydrogenase; MELD, model for end-stage liver disease; PLT, platelets; PMNLs, polymorphnuclear leukocytes; SAAG, serum-ascites albumin gradient; SBP, spontaneous bacterial peritonitis; TLC, total leukocytic count; WBC, white blood cell. *Significant difference $(P<0.05)$. ${ }^{*}$ Highly significant.

Table 7 Validity of ascitic fluid calprotectin in detection of spontaneous bacterial peritonitis

\begin{tabular}{lcccccc}
\hline Variables & $\begin{array}{c}\text { Cutoff } \\
\text { point }\end{array}$ & AUC & Sensitivity & Specificity & PPV & NPV \\
\hline $\begin{array}{l}\text { Ascitic fluid } \\
\text { calprotectin } \\
\text { (ng/ml) }\end{array}$ & 620 & 0.967 & 90.91 & 95.45 & 95.2 & 91.3 \\
\hline
\end{tabular}

AUC, area under curve; NPV, negative predictive value; PPV, positive predictive value.

responsible for up to $60 \%$ of soluble protein content in the cytosol of neutrophil [9].

A high level of calprotectin increase in extracellular fluid during different inflammatory conditions like SBP [8]. Ascitic fluid calprotectin can detect PMNLs count more than 250 cell/ $\mathrm{mm}^{3}$, which may be helpful in the diagnosis of SBP [7].

Whereas, a delay in antibiotic therapy lead to an increase in mortality rate. In addition to the diagnostic tools available, multiple efforts have been developed for a rapid diagnosis of SBP. So this study was conducted to assess the role of ascitic fluid calprotectin level for diagnosis of SBP and to identify a cutoff level of ascitic fluid calprotectin that can be used for development of a rapid bedside test.

In this study, SBP was found to be more common in males than in females, a result that goes in agreement with the result obtained by Reiberger et al. [14], who reported that SBP was increased in male. The male predominance in our study may be due to higher incidence of bilharziasis and $\mathrm{HCV}$ in our locality.

In the current study, the most common clinical presentation in patients with SBP was fever (72.7\%). These results were consistent with Paul et al. [15], who detected that, most patients of SBP have signs clearly suggestive of peritoneal infection, especially fever, so fever is considered one of the characteristic sign of SBP.

The majority of our patients ( $75 \%$ of patients) suffered from liver cirrhosis due to chronic hepatitis $\mathrm{C}$. These results were consistent with Mohamoud et al. [16], who concluded that the most common cause of cirrhosis in Egypt is hepatitis $\mathrm{C}$ virus infection, with the highest prevalence rate worldwide.

The culture results showed growth of E. coli (12 isolates) followed by $S$. viridans (six isolates) and $K$. pneumoniae (two isolates) and S. aureus (two isolates). This finding is in concordance with Rimola et al. [17], who reported that common bacteria responsible for SBP are E. coli (37\%), S. viridans (10\%) and Klebsiella spp. $(6 \%)$.

We found that, the majority of SBP patients were Child-Pugh class C (68.2\%). This result matched with that reported by Cirera et al. [18], who reported that, Child class $\mathrm{C}$ was reported in $70 \%$ of the patients who had developed SBP. 
There was a significant increase of MELD score in patients with SBP $(P=0.034)$ with mean value $(18.70$ $\pm 7.42)$. Also, Kraja et al. [19], observed that individuals with moderate to high MELD score presented a greater risk for the SBP development.

In the current study, SBP group showed highly statistically significant increase in serum TLC when compared to non-SBP groups $(P=0.000)$. Similar result was obtained by Cholongitas et al. [20], who reported that leukocytosis was higher in SBP patients as a part of reaction of the body against infection. There was reduced platelets count in SBP and non-SBP but it was much lower in SBP group with highly significant difference between both the groups $(P=0.000)$. These results are consistent with those of Lata et al. [21], who reported significantly lower platelet counts in a group of SBP patients, when compared to ascitic patients without this infection and supposed that the decrease of platelet count in SBP reflects the increase of portal pressure, portal hypertension could probably contribute to the amount of protein in ascites, which is an important factor influencing the incidence of SBP even by increasing bacterial translocation. Also, Kuckleburg et al. [22], suggested that platelets have numerous immunological functions as their role in activating neutrophil granulocytes in bacterial infections. Thus, a thrombocytopenia might cause an insufficient activation of neutrophils and increased risk of infections in cirrhotic patients.

Also we found that, the level of serum ALT, AST was significantly higher in cirrhotic patients with SBP group than non-SBP group ( $P=0.000$ and 0.005 , respectively). These results were in line with De Mattos et al. [23], who strongly suggested that liver function may be deteriorated by bacterial infection. Also Ruiz-delArbol et al. [24] found that SBP patients frequently developed a progressive rapid impairment in systemic hemodynamics, worsening liver failure.

Also, there was a significantly higher serum bilirubin in SBP group when compared to non-SBP group $(P=0.000)$. Also Tsung et al. [25] reported that a higher level bilirubin in SBP patients showed higher mortality.

In the current study, serum albumin level in SBP groups was statistically significantly lower than in non-SBP group $(P=0.00)$. This result was also obtained by Ruiz-del-Arbol et al. [24], who found that patients with SBP develop a rapid deterioration and impairment in hemodynamics, leading to aggravation of liver cell failure (LCF).
Also INR was significantly high in SBP patients more than non-SBP patients $(P=0.005)$. Similar results were concluded by Oladimeji et al. [26], who reported that, international normalization ratio (INR) was significantly higher in those patients with SBP compared with those without $\mathrm{SBP}$ and this indicate poor prognosis in SBP patients.

The level of serum creatinine was significantly increased in patients with SBP when compared to non-SBP patients $(P=0.003)$ and this result goes in agreement with Angeloni et al. [27], who concluded that the hospital mortality in SBP is high due to renal impairment, which is common in SBP patients either due to prerenal or hepatorenal causes and also reinforced by Tsung et al. [25], who stated that renal dysfunction occurs in patients with SBP and it is independent predictor of mortality.

Chemical analysis of ascitic fluid showed significantly higher levels of TLC, PMNLs count in SBP group compared to non-SBP group $(P=0.000)$, these results were in line with Yildirim et al. [28], who reported higher ascitic TLC in SBP more than non-SBP patients. Also, Jansen [29] stated that, although ascitic TLC count increases in SBP cases, it suffers from low specificity because a large proportion of patients with sterile ascites have increased TLC. Also diuretic therapy may increase the TLC count but does not cause change in the PMNLs count.

Ascitic fluid total protein in our study was significantly high in SBP patients versus non-SBP patients $(P=0.000)$. Also, Abdel-Razik et al. [30], found that, ascitic fluid total protein was significantly increased in SBP patients, which may have an important role in the inflammatory process in SBP, so it can be measured as an early inflammatory marker of the disease.

Also ascitic fluid LDH, was significantly higher in SBP patients than in non-SBP patients $(P=0.000)$, similar results were obtained by Krastev et al. [31], who found that, in patients with SBP, ascitic fluid LDH is higher in SBP than non-SBP group.

Our study revealed that ascitic fluid calprotectin was detected in both groups. But there was high statistically significant increase in ascitic fluid calprotectin in SBP group when compared with non-SBP group (781.23 \pm 165.94 and $294.91 \pm 217.48)$, respectively $(P=0.000)$. A result that is consistent with those demonstrated in the studies of Elbanna et al. [32] and Ali et al. [33] Also 
Abdel-Razik et al. [30], showed that, ascitic fluid calprotectin was significantly higher in SBP patients.

A significant positive correlation was observed between ascitic fluid calprotectin and $\mathrm{WBC}$ in blood among SBP group $(P=0.000)$, this result was in consistence with Fernandes et al. [34], who found that, WBC in blood and ascitic calprotectin increased in patient with SBP as a part of immune reaction against infection. But, there was a significant negative correlation between ascitic calprotectin and serum albumin among SBP group $(P=0.000)$, this result was in agreement with Burri et al. [7], who said that, ascitic calprotectin increased in SBP patients with decreased level in serum albumin and this correlation showed the reason why $\mathrm{SBP}$ is common in hepatic patient with severe hepatic failure and low synthetic function.

Further analysis of results revealed, high significant positive correlation between ascetic fluid calprotectin and ascitic fluid TLC and PMNLs among SBP group $(P=0.000)$. Similar results were obtained by Soyfoo et al. [9], who concluded that calprotectin was detected mainly in neutrophils, and its presence in the body fluids is proportional to the rate of flow of neutrophils. This is in agreement with Burri et al. [7], who found that, ascetic fluid calprotectin was helpful in detection of neutrophil count.There was also a significant positive correlation between ascitic fluid calprotectin and ascitic fluid total protein among SBP group $(P=0.036)$. This result was in line with Ali et al. [33], who found a significant positive correlation between ascitic fluid calprotectin and ascitic fluid protein and $\mathrm{WBC}$ count among SBP patients.

While in the current study, there was a significant negative correlation between ascetic calprotectin and ascitic fluid albumin among SBP group $(P=0.003)$, this result was in agreement with Gupta et al. [35], who explained that, in cirrhotic patient, there was a decrease in synthetic function of the liver, which was aggravated by sepsis. The net result was decreased serum albumin, which by its role decreased the diffused albumin to ascitic fluid.

A significant positive correlation was detected between ascitic fluid calprotectin and MELD score values among the SBP group $(P=0.000)$, this result was consistent with Abdel-Razik et al. [30], who reported that ascitic calprotectin was an important marker for the diagnosis of SBP and its level in ascitic fluid help in detection of the degree of severity of the liver disease.

The current study demonstrated that, ascitic calprotectin with cutoff value of $620 \mathrm{ng} / \mathrm{ml}$, had sensitivity (90.91\%) and specificity (95.45\%), with PPV (95.2\%) and NPV (91.3\%) in diagnosis of SBP.

Fernandes et al. [34], found that, an optimal cutoff of calprotectin above $1.57 \mu \mathrm{g} / \mathrm{ml}$ presented sensitivity (87.8\%), specificity (97.9\%), PPV (97.3\%), and NPV (90.2\%) for diagnosing SBP.

Also, Abdel-Razik et al. [30], showed that, at a cutoff value of $445 \mathrm{ng} / \mathrm{ml}$, ascitic fluid calprotectin had sensitivity (95.4\%) and specificity (85.2\%) for detecting SBP.

This prospective study evaluated the diagnostic utility of measuring ascitic fluid calprotectin to identify ascitic PMNLs count more than $250 / \mathrm{mm}^{3}$ in patients referred to paracentesis. We found that, patients with an elevated PMNLs count $\left(>250 / \mathrm{mm}^{3}\right)$ had higher ascitic calprotectin levels than those with normal cell counts. This finding indicated that, ascitic calprotectin levels well and reliably correlated it with PMNLs count.

It is clinically significant that, calprotectin levels in ascitic patients can identify elevated PMNLs count using enzyme-linked immunosorbent assay methods. Indeed, ascitic calprotectin may serve as a good marker for PMNLs count and would be amenable to routine SBP screening, especially when measured by a bedside test.

The current study had several limitation. First, all patients with ascites were included, irrespective of the etiology. Second, our sample size was small while larger studies are needed to evaluate ascitic fluid calprotectin as a diagnostic marker for SBP and to establish a reliable cutoff for optimal identification of PMNLs counts more than $250 / \mathrm{mm}^{3}$.

\section{Conclusion}

Ascitic fluid calprotectin was significantly elevated in $\mathrm{SBP}$ patients in comparison with non-SBP patients. In addition, they also correlate well with the PMNLs count and protein levels in ascitic fluid and reliably diagnose SBP.

\section{Acknowledgements}

The authors thank all the staff in the Faculty of Medicine, Zagazig University for their assistance in conducting this study.

\section{Financial support and sponsorship}

Nil. 


\section{Conflicts of interest}

There are no conflicts of interest.

\section{References}

1 Soriano G, Castellote J, Álvarez C, Girbau A, Gordillo J, Baliellas C, et al. Secondary bacterial peritonitis in cirrhosis: a retrospective study of clinical and analytical characteristics, diagnosis and management. J Hepatol 2010; 52:39-44.

2 Runyon BA. Ascites and spontaneous bacterial peritonitis. In: Feldman M, Scharachmidt BF, Sleisenger MH (editors) Sleisenger and Fordtran's gastrointestinal and liver disease: pathophysiology, diagnosis, management. Philadelphia, PA: WB Saunders 1998. 1310-1333

3 Wiest R, Krag A, Gerbes A. Spontaneous bacterial peritonitis: recent guidelines and beyond. Gut 2012; 61: 297-310.

4 Mandorfer M, Bota S, Schwabl P, Bucsics T, Pfisterer N, Kruzik M, et al. Nonselective $\beta$ blockers increase risk for hepatorenal syndrome and death in patients with cirrhosis and spontaneous bacterial peritonitis. Gastroenterology 2014; 146:1680-1690.

5 Singal AK, Salameh H, Kamath PS. Prevalence and in-hospital mortality trends of infections among patients with cirrhosis: a nationwide study of hospitalised patients in the United States. Aliment Pharmacol Ther 2014; 40:105-112.

6 European Association for the Study of the Liver (EASL). EASL clinical practice guidelines on the management of ascites, spontaneous bacterial peritonitis, and hepatorenal syndrome in cirrhosis. J Hepatol 2010; 53:397-417.

7 Burri E, Schulte F, Muser J, Meier R, Beglinger C. Measurement of calprotectin in ascitic fluid to identify elevated polymorphonuclear cell count. World J Gastroenterol 2013; 19:2028-2036.

8 Brophy MB, Nolan EM. Manganese and microbial pathogenesis: sequestration by the Mammalian immune system and utilization by microorganisms. ACS Chem Biol 2015; 10:641-651.

9 Soyfoo MS, Roth J, Vogl T, Pochet R, Decaux GUY. Phagocytespecific S100A8/A9 protein levels during disease exacerbations and infections in systemic lupus erythematosus. J Rheumatol 2009; 36:2190-2194.

10 Friedman S, Schiano T. Cirrhosis and its sequelae. Cecil textbook of medicine. 22nd ed. Philadelphia, PA: Saunders 2004. 936-944

11 Thévenot T, Cadranel JF, Nguyen-Khac E, Tilmant L, Tiry C, Welty S, et al. Diagnosis of spontaneous bacterial peritonitis in cirrhotic patients by use of two reagent strips. Eur J Gastroenterol Hepatol 2004; 16:579-583.

12 Gines P, Arroyo V, Rodes J. Therapy of ascites and spontaneous bacterial peritonitis. Therapy of digestive disorders: a companion to Sleisenger and Fortran's gastrointestinal and liver disease. Philadelphia, PA: Saunders 2000. 373-384

13 Runyon BA. Management of adult patients with ascites due to cirrhosis: an update. Hepatology 2009; 49:2087-2107.

14 Reiberger T, Schwabl P, Bucsics T, Soucek K, Payer BA, Blacky A, et al. Microbial epidemiology; risk factors and outcome of SBP in cirrhotic patients with ascites. Z Gastroenterol 2012; 50:P41.

15 Paul K, Kaur J, Kazal HL. To study the incidence, predictive factors and clinical outcome of spontaneous bacterial peritonitis in patients of cirrhosis with ascites. J Clin Diagn Res 2015; 9:OC09.

16 Mohamoud YA, Mumtaz GR, Riome S, Miller D, Abu-Raddad LJ. The epidemiology of hepatitis $C$ virus in Egypt: a systematic review and data synthesis. BMC Infect Dis 2013; 13:288.
17 Rimola A, García-Tsao G, Navasa M, Piddock LJ, Planas R, Bernard B, et al. Diagnosis, treatment and prophylaxis of spontaneous bacterial peritonitis: a consensus document. J Hepatol 2000; 32:142-153.

18 Cirera I, Bauer TM, Navasa M, Vila J, Grande L, Taurá P, et al. Bacterial translocation of enteric organisms in patients with cirrhosis. J Hepatol 2001; 34:32-37.

19 Kraja B, Sina M, Mone I, Pupuleku F, Babameto A, Prifti S, et al. Predictive value of the model of end-stage liver disease in cirrhotic patients with and without spontaneous bacterial peritonitis. Gastroenterol Res Pract 2012; 2012:539059.

20 Cholongitas E, Papatheodoridis GV, Manesis EK, Burroughs AK, Archimandritis AJ. Spontaneous bacterial peritonitis in cirrhotic patients: Is prophylactic propranolol therapy beneficial?. J Gastroenterol Hepatol 2006; 21:581-587.

21 Lata J, Fejfar T, Krechler T, Musil T, Husová L, Šenkyrík M, et al. Spontaneous bacterial peritonitis in the Czech Republic: prevalence and aetiology. Eur J Gastroenterol Hepatol 2003; 15:739-743.

22 Kuckleburg CJ, Tiwari R, Czuprynski CJ. Endothelial cell apoptosis induced by bacteria-activated platelets requires caspase- 8 and- 9 and generation of reactive oxygen species. Thromb Haemost 2008; 99:363-372.

23 De Mattos AA, Coral GP, Menti E, Valiatti F, Kramer C. Bacterial infection in cirrhotic patient. Arq Gastroenterol 2003; 40:11-15.

24 Ruiz-del-Arbol L, Urman J, Fernández J, González M, Navasa M, Monescillo A, et al. Systemic, renal, and hepatic hemodynamic derangement in cirrhotic patients with spontaneous bacterial peritonitis. Hepatology 2003; 38:1210-1218.

25 Tsung PC, Ryu SH, Cha IH, Cho HW, Kim JN, Kim YS, et al. Predictive factors that influence the survival rates in liver cirrhosis patients with spontaneous bacterial peritonitis. Clin Mol Hepatol 2013; 19:131-139.

26 Oladimeji AA, Temi AP, Adekunle AE, Taiwo RH, Ayokunle DS. Prevalence of spontaneous bacterial peritonitis in liver cirrhosis with ascites. Pan Afr Med J 2013; 15:128-136.

27 Angeloni S, Leboffe C, Parente A, Venditti M, Giordano A, Merli M, et al. Efficacy of current guidelines for the treatment of spontaneous bacterial peritonitis in the clinical practice. World J Gastroenterol 2008; 14:2757-2762.

28 Yildirim B, Sari R, Isci N. Patients with spontaneous bacterial peritonitis, and malignant and cirrhotic ascites. J Natl Med Assoc 2005; 97:276-280.

29 Jansen PLM. Spontaneous bacterial peritonitis detection, treatment and prophylaxis in patients with liver cirrhosis. Neth J Med 1997; 51:123-128.

30 Abdel-Razik A, Mousa N, Elhammady D, Elhelaly R, Elzehery R, Elbaz S, et al. Ascitic fluid calprotectin and serum procalcitonin as accurate diagnostic markers for spontaneous bacterial peritonitis. Gut Liver 2016; 10:624-631.

31 Krastev N, Djurkov V, Murdjeva M, Akrabova P, Karparova T, Penkov V, et al. Diagnosis of spontaneous and secondary bacterial peritonitis in patients with hepatic cirrhosis and ascites. Khirurgiia (Sofiia) 2013; 3:20-25.

32 Elbanna A, Allam N, Hossam N, Ibrahim A, Wagdy M. Plasma and ascitic fluid level of calprotectin in chronic liver disease: malignant and nonmalignant. Bull Alex Fac Med 2008; 44:647-653.

33 Ali AG, Ahmed NS, Hasan SM. Calprotectin measurement in ascitic fluid: a new test for the rapid diagnosis of spontaneous bacterial peritonitis. Med $\mathrm{J}$ Cairo Uni 2013; 81:53-56.

34 Fernandes SR, Santos P, Fatela N, Baldaia C, Tato Marinho R, Proença H, et al. Ascitic calprotectin is a novel and accurate marker for spontaneous bacterial peritonitis. J Clin Lab Anal 2016; 30:1139-1145.

35 Gupta R, Misra SP, Dwivedi M, Misra V, Kumar S, Gupta SC. Diagnosing ascites: value of ascitic fluid total protein, albumin, cholesterol, their ratios, serum-ascites albumin and cholesterol gradient. J Gastroenterol Hepatol 1995; 10:295-299. 